\title{
Trust between specialists and family physicians
}

$\mathrm{R}$ eferrals from family physicians to specialists can encounter obstacles, such as long waiting lists and limited resources. However, an issue that is seldom discussed is that of trust between the doctors.

Because time for appointments can be limited, specialists often need to evaluate how they will prioritize a referral from a family physician. Thus, it is important for specialists to trust the intuition of family physicians to know when something is wrong with their patients - a special skill that comes with knowing a patient over time.

My education on the relationships between family physicians and specialists began during my neurology residency. I was sound asleep when the telephone rang with a call for my wife, a family physician. I dozed while she spoke with an anxious family. After she hung up, I received a sharp elbow to the ribs. "Who do you think they call at 3:00 am when things are going bad?" she asked. "Why didn't you tell me that you discharged Mr. X after an air study?"

A few years later, as a young consultant on the neurology service at a tertiary care hospital, I was paged at about $08: 30$ by one of the family physicians in town. "Dave," he said, "I think I have a kid with early meningitis. Could you have a look at him?"

Half an hour later, a teenaged boy presented to the emergency department. He looked unwell, had a headache, was slightly febrile $\left(38.5^{\circ} \mathrm{C}\right)$ and did not show any meningism. However, because this good family physician suspected meningitis, I did a lumbar puncture and was surprised to see 200 leukocytes and gram-positive cocci (they turned out to be pneumococci). The boy was given penicillin and recovered well. A couple of days later, I phoned the family physician to tell him that his patient had done so well precisely because he had picked up the meningitis so early. I asked him how on earth he had done it.

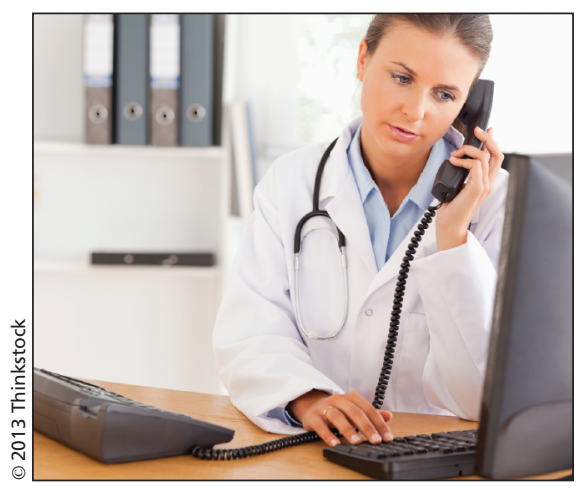

"What do you mean?" he asked.

"Well," I replied, "You phoned at 08:30, and your office wasn't open until 09:00, so how did you pick it up?"

"Oh, well, I had seen him in the office the evening before with a sore throat and a headache; he had no neck stiffness and his fundi were normal, but I told his mother to call me if he got worse".

"Wait a minute: How many patients did you see in the past month with a headache and a sore throat?"

"Oh, about a hundred."

"And in how many of those did you look in the fundi, and check for a stiff neck?"

"Oh; just him."

"But why?"

"Oh; because he was acting like a smartass, and it wasn't like him!"

Only a family physician who knows the patient could recognize such a personality change, which was the key to the successful management of this patient's condition. A teenaged boy behaving impudently in a walk-in clinic would have had no chance of such an early diagnosis.

About 25 years later, I received a telephone call from a family physician about a 3 hours' drive from my hospital. She told me that she had seen a young woman with the sudden onset of a very severe headache. Concerned about subarachnoid hemorrhage, the doctor had arranged for computed tomography in a nearby town. The results were negative, so she had gone on to do a lumbar puncture, which also had negative results. There was no evidence of subarachnoid hemorrhage. "But," she said, "There is something wrong. I know this patient very well, and there is something wrong with her." My alarm bells went off; my reaction was that I must pay attention.

I asked the doctor to send the patient to the emergency department at our hospital. On arrival, the patient looked sick and was in considerable distress with headache, but there were no localizing features. The optic fundi suggested raised intracranial pressure.

Besides subarachnoid hemorrhage, an important cause of thunderclap headache is thrombosis of the cerebral venous sinuses. Magnetic resonance imaging showed complete thrombosis of all of the cerebral venous sinuses. A catheter was placed in the sagittal sinus, and tissue plasminogen activator was infused over 1 hour. The venous sinuses were restored to normal function. In the morning, in the intensive care unit, the patient's first statement was that the pressure in her head was gone. There is no doubt that she would have died without treatment.

It is important for specialists to trust the instincts of family physicians. Only a family physician who has known a patient over time is able to make these kinds of judgments. One important deficiency of care by walk-in clinics is that there is no such advantage afforded to physicians.

\section{J. David Spence MD}

Stroke Prevention \& Atherosclerosis

Research Centre

Robarts Research Institute, Western

University

London, Ont.

\section{CMAJ 2013. DOI:10.1503/cmaj.131079}

Do you have an opinion about this article? Post your views at www.cmaj.ca. Potential Salon contributors are welcome to send a query to salon@ cmaj.ca. 